\title{
Bentuk Tindak Tutur Ilokusi dalam Program Ini Talk Show NET TV
}

\author{
Siti Nurkhalizah S*, I Wayan Simpen, Ni Putu N. Widarsini \\ Sastra Indonesia, Fakultas Ilmu Budaya, Universitas Udayana \\ [lizhasilalahi07@gmail.com] \\ Denpasar, Bali, Indonesia \\ *Corresponding Author
}

\begin{abstract}
This research is entitled "Illocutionary Speech Acts in This Program Talk Show NET TV". The purpose of this study is to describe the forms of speech acts of illocution and speech strategies contained in this program. This research uses the illocutionary speech act theory proposed by Searle and the speech strategy proposed by Blum-Kulka. At the data collection stage the listening method is used to help with the note taking technique. Stages of data analysis using contextual methods. The stage of presenting the results of data analysis using formal and informal methods. In this program, NET TV Talk Show found five types of illocutionary acts, namely assertive, directive, expressive, commissive, and declarative. There are five data as assertive acts, eleven data are directive, ten data are expressive, four data are commissive, and three data are declarative. This study found three types of speech strategies, namely direct speaking strategies, indirect speaking strategies, and signaling strategies. There are five data are direct speaking strategies, three data are indirect speaking strategies, and two data are signaling strategies.
\end{abstract}

Keywords: illocutionary acts, speech strategies, pragmatic, and this talk show

\begin{abstract}
Abstrak
Penelitian ini berjudul "Bentuk Tindak Tutur Ilokusi dalam Acara Ini Talk Show NET TV". Tujuan penelitian ini adalah mendeskripsikan bentuk-bentuk tindak tutur ilokusi dan strategi bertutur yang terdapat pada acara Ini Talk Show NET TV. Penelitian ini menggunakan teori tindak tutur ilokusi yang dikemukakan oleh Searle dan strategi bertutur yang dikemukakan oleh Blum-Kulka. Pada tahapan pengumpulan data digunakan metode simak di bantu dengan teknik catat. Tahapan analisis data menggunakan metode kontekstual. Tahap penyajian hasil analisis data menggunakan metode formal dan informal. Pada acara Ini Talk Show NET TV ini ditemukan lima jenis tindak ilokusi, yaitu asertif, direktif, ekspresif, komisif, dan deklaratif. Terdapat lima data merupakan tindak asertif, sebelas data merupakan direktif, sepuluh data merupakan ekspresif, empat data merupakan komisif, dan tiga data merupakan deklaratif. Penelitian ini menemukan tiga jenis strategi bertutur, yaitu strategi bertutur langsung, strategi bertutur tidak langsung, dan strategi bertutur dengan isyarat. Terdapat lima data merupakan strategi bertutur langsung, tiga data merupakan strategi bertutur tidak langsung, dan dua data merupakan strategi bertutur dengan isyarat.
\end{abstract}

Kata kunci: tindak ilokusi, strategi bertutur, pragmatik, dan Ini Talk Show 


\section{PENDAHULUAN}

Manusia adalah makhluk sosial yang berinteraksi dengan sesama. Interaksi itu dapat dilakukan dengan berkomunikasi secara lisan dan tulisan. Komunikasi lisan dalam konteks dan situasinya memerlukan strategi tertentu untuk mendapatkan hasil komunikasi yang diharapkan. Dalam berkomunikasi tentu tidak terlepas dengan tindak tutur. Tindak tutur merupakan kajian ilmu pragmatik, tindak tutur adalah tindakan yang ditampilkan melalui tuturan.

Acara talk show dapat dimanfaatkan dalam penelitian pragmatik. Hal ini disebabkan oleh adanya tindak tutur dan strategi bertutur dalam talk show. Oleh karena itu, tindak tutur dalam acara talk show dapat di analisis bentuk-bentuk dan strategi bertutur tuturnya. Penelitian ini menggunakan teori tindak ilokusi yang dikemukakan Searle dan strategi bertutur yang dikemukakan Blum-Kulka.

Ada tiga jenis tindakan yang dapat diwujudkan oleh seorang penutur, yaitu tindak lokusi, tindak ilokusi, dan tindak perlokusi. Tindak lokusi adalah tindak tutur yang diucapkan untuk menyatakan sesuatu. Tindak ilokusi adalah tindakan yang digunakan untuk melakukan suatu hal untuk maksud dan fungsi tertentu. Tindak perlokusi adalah efek yang akan ditimbulkan oleh ungkapan penutur kepada mitra tutur. Penelitian ini hanya fokus pada tindak tutur ilokusi karena sangat berkaitan erat dengan objek penelitian yaitu tindak tutur dalam program talk show. Searle (dalam Rahardi, 2009:17) membagi tindak ilokusi menjadi lima bentuk yaitu, asertif, direktif, ekspresif, komisif, dan deklaratif.

Strategi bertutur adalah rencana yang patut dilakukan untuk kelancaran komunikasi. Strategi bertutur dibedakan menjadi tiga macam, yaitu strategi bertutur langsung, strategi bertutur tidak langsung, dan strategi bertutur dengan isyarat.
Acara Ini Talk Show NET TV dipilih sebagai objek penelitian karena memuat tindak tutur yang sebagian besar menggunakan bahasa sehari-hari dan mudah dimengerti oleh berbagai kalangan. Acara Ini Talk Show juga dikemas dengan suasana santai sehingga banyak disukai oleh remaja hingga orang dewasa. Pada acara Ini Talk Show cukup banyak terdapat tuturan tokoh-tokoh yang mengandung tindak tutur ilokusi yang mencakup asertif, direktif, ekspresif, komisif, dan deklaratif.

Berdasarkan uraian di atas, dapat dirumuskan prmasalahan dalam penelitian ini. Adapun masalah yang diangkat adalah sebagai berikut.

a. Bagaimanakah bentuk-bentuk tindak tutur ilokusi yang terdapat dalam acara Ini Talk Show di NET TV?

b. Strategi bertutur apa sajakah yang terdapat dalam acara Ini Talk Show di NET TV?

Setiap penelitian yang dilakukan memiliki tujuan yang ingin dicapai. Penelitian ini memiliki tujuan mendeskripsikan bentuk-bentuk tindak tutur ilokusi yang terdapat pada acara Ini Talk Show NET TV, dan mendeskripsikan strategi bertutur yang terdapat pada acara Ini Talk Show NET TV.

\section{METODE}

Metode dan teknik yang digunakan dalam penelitian ini ada tiga, yaitu metode dan teknik pengumpulan data, analisis data, dan penyajian hasil analisis data. Ketiga metode tersebut diuraikan sebagai berikut. Metode pengumpulan data pada penelitian ini menggunakan metode simak bebas libat cakap. Metode ini merupakan metode yang tidak melibatkan peneliti dalam tuturan, artinya peneliti tidak ikut serta dalam pembicaraan orang-orang yang berbicara (Sudaryanto, 1993:134). Metode yang digunakan dalam analisis data adalah metode kontekstual. Metode kontekstual 
merupakan cara analisis data yang diterapkan dengan mendasar, memperhitungkan, dan menghubungkan konteks (Rahardi, 2005:16). Data yang sudah terkumpul dianalisis dengan cara pentranskripsian data, pemilihan data, penganalisisan data, pemaknaan data, dan penyajian data. Hasil analisis data penelitian ini disajikan melalui dua cara, yaitu metode informal dan metode formal. Metode informal adalah perumusan dengan kata-kata biasa, sedangkan metode formal adalah perumusan dengan tanda dan lambanglambang (Sudaryanto, 1993:145).

\section{HASIL DAN PEMBAHASAN}

Pada tindak tutur Ini Talk Show NET TV terdapat lima jenis bentuk tindak tutur ilokusi dan tiga macam strategi bertutur. Bentuk-bentuk dan strategi bertutur tersebut dijelaskan sebagai berikut.

\section{Bentuk-Bentuk Tindak Tutur Ilokusi yang Terdapat pada Acara Ini Talk Show NET TV}

Tindak tutur merupakan unsur pragmatik yang melibatkan pembicara, pendengar atau penulis, pembaca, serta yang dibicarakan. Menurut Searle (dalam Wijana, 1996:17), dinyatakan bahwa secara pragmatis ada tiga jenis tindakan yang dapat diwujudkan oleh seorang penutur, yakni tindak lokusi, tindak ilokusi, dan tindak perlokusi.

Searle (dalam Leech, 1993:164--166) membagi tindak tutur menjadi lima kategori yaitu asertif, direktif, ekspresif, komisif, dan deklaratif. Dalam video streaming yotube acara Ini Talk show ditemukan kelima jenis tindak ilokusi yang ditemukan oleh Searle.

\section{Asertif}

Asertif, yaitu tindak tutur yang mengikat penuturnya kepada kebenaran atas apa yang dikatakannya.
Contoh:

Data Tuturan 1

Jokowi: Ya saya tau, Bu Jokowi ini senengnya duren. Saya belikan duren, saya pilihkan, saya minta yang mahal mana? yg bagus mana? Bagus dan mahal. Ya bawa pulang satu saja itu.

Konteks: Pada episode ini membahas buah kesukaan Ibu Iriana dan Bapak Jokowi menjadikan buah durian sebagai kado spesial untuk Ibu Iriana pada hari ulang tahunnya yang ke 55 .

Data tuturan 1 diambil pada episode "Spesial Keluarga Bapak Jokowi: Ibu Iriana adalah Cinta Pertama Pak Jokowi". Berdasarkan penanda yang ditemukan pada tuturan, data tuturan 1 merupakan tindak tutur ilokusi asertif. Tuturan yang diucapkan oleh Pak Jokowi mendeskripsikan makanan kesukaan Ibu Iriana tentang buah kesukaannya dan mendeskripsikan buah durian seperti apa yang dihadiahkannya untuk Ibu Iriana. Secara singkat dapat dikatakan bahwa tindak tutur tersebut adalah ujaran yang menunjukkan pendeskripsian sehingga tindak tutur tersebut dapat disebut sebagai tindak tutur asertif.

\section{Direktif}

Direktif, yaitu tindak ujaran yang dilakukan penuturnya dengan maksud agar mitra tutur melakukan tindakan yang disebutkan di dalam ujaran itu.

Contoh:

Data Tuturan 6

Jokowi: Jadi gini ya mas Sule ya yang namanya RT, yang namanya RW, yang namanya lurah, yang namanya camat, yang namanya bupati, walikota, gubernur, menteri, presiden, semua itu harus melayani rakyat.

Konteks: Tayangan ini menunjukkan Sule melaporkan sikap pak RT ke Pak Jokowi tentang pemungutan liar dan pelayanan terhadap rakyat. Di sini Pak Jokowi meminta agar seluruh perangkat negara melayani rakyat. 
Data tuturan 6 diambil pada episode "Spesial Keluarga Bapak Jokowi: Bolot Kaget di rumah Sule ada Presiden Jokowi”). Berdasarkan penanda yang ditemukan pada tuturan, data tuturan 6 merupakan tindak tutur ilokusi direktif. Pada tindak tutur ilokusi direktif ini, tuturan yang diutarakan bermaksud agar mitra tutur melakukan sesuatu. Pada data tuturan 6, tuturan yang diucapkan oleh Pak Jokowi mempunyai maksud untuk meminta RT, RW, lurah, camat, bupati, wali kota, gubernur, menteri, dan presiden untuk turut melayani rakyat untuk menciptakan perubahanperubahan.

\section{Ekspresif}

Ekspresif, yaitu tindak ujaran yang dilakukan dengan maksud agar ujarannya diartikan sebagai evaluasi tentang hal yang disebutkan di dalam ujaran itu.

Contoh:

\section{Data Tuturan 17}

Sule : Ciri khas Bapak kalau ketawakan begitu. Saya sangat bangga Pak, bangga sekali tak terhingga Bapak mau singgah di rumah saya. Bagaimana Pak tadi perjalanan dari istana atau dari mana pak? Oohhh, dari istana ya, mungkin gabisa ngomong karena ketutup sama helm ya Pak.

Konteks: Pada tuturan ini dibahas Andre yang berpura-pura menjadi Pak Jokowi ke rumah Sule yang pada malam itu Pak Jokowi menjadi bintang tamu di acara Ini Talk show.

Data tuturan 17 diambil pada episode "Spesial Keluarga Bapak Jokowi: Bolot Kaget di rumah Sule ada Presiden Jokowi”. Berdasarkan penanda yang ditemukan pada tuturan, data tuturan 17 merupakan tindak tutur ilokusi direktif. Pada tuturan 17, tuturan yang diucapkan oleh Sule merupakan sebuah ungkapan terima kasih kepada Bapak Jokowi yang berkenan hadir di rumah Sule.

\section{Komisif}

Komisif, yaitu tindak ujaran yang mengikat penuturnya untuk melaksanakan apa yang disebutkan di dalam ujarannya.

Contoh:

Data Tuturan 27

Sule : Ngevlog keluarga juga silahkan, biasakan sama bapak ngevlog. Kaesang ini jago panco ya Pak ya? Bisa lawan saya mas kaesang?

Konteks: Tuturan ini membahas Andre yang berpura-pura menjadi Kaesang yang hadir ke rumah Sule. Sule mempersilakan Andre untuk membuat video vlog bersama keluarganya.

Data tuturan 27 diambil pada episode "Spesial Keluara Bapak Jokowi: Jan Ethes Bilang Sule Menakutkan". Berdasarkan penanda yang ditemukan pada tuturan, data tuturan 27 merupakan tindak tutur ilokusi komisif. Tuturan yang diucapkan oleh Sule merupakan sebuah penawaran kepada Andre yang saat itu menjadi Kaesang (anak bungsu Pak Jokowi) untuk ngevlog karena seperti yang diketahui Kaesang sering kali membagikan video vlognya di youtube ketika dia sedang bersama keluarganya.

\section{Deklaratif}

Deklaratif, yaitu tindak ujaran yang dilakukan penutur dengan maksud untuk menciptakan hal yang baru.

Contoh:

Data Tuturan 31

Jokowi: Jadi gini ya mas Sule ya yang namanya RT, yang namanya RW, yang namanya lurah, yang namanya camat, yang namanya bupati, walikota, gubernur, menteri, presiden, semua itu harus melayani rakyat.

Konteks: Tayangan ini menunjukkan Pak Jokowi menegaskan bahwa yang namanya perangkat negara, baik kota maupun daerah, harus turut melayani rakyat.

Data tuturan 31 diambil pada episode "Spesial Keluara Bapak Jokowi: Bolot 
Kaget di rumah Sule ada Presiden Jokowi”. Berdasarkan penanda yang ditemukan pada tuturan, data tuturan 31 merupakan tindak tutur ilokusi deklaratif. Kalimat yang diucapkan oleh Pak Jokowi memutuskan bahwa sikap perangkatperangkat negara seharusnya siap untuk melayani rakyat.

\section{Strategi Bertutur yang Terdapat dalam Program Ini Talk Show NET TV}

Strategi bertutur dibedakan menjadi tiga macam, yaitu bertutur secara langsung, bertutur secara tidak langsung, dan bertutur dengan menggunakan isyarat.

\section{Strategi Bertutur Langsung}

Strategi bertutur langsung adalah tuturan yang menggunakan modus kalimat yang secara konvensional sesuai dengan fungsinya.

Contoh:

Sule: Maaf ini Pak, biar gak kepanasan, biar saya juga bisa langsung bertatap muka dengan Bapak enak. Bisa di buka Pak mungkin helm nya!

Pada tuturan di atas Sule meminta Andre untuk melepaskan helmnya. Andre melepas jasnya. Sule mengingatkan sekali lagi melepas helm. Tuturan di atas menyiratkan adanya strategi bertutur. Strategi yang digunakan adalah strategi bertutur langsung dengan modus kalimat imperatif.

\section{Strategi Bertutur Tidak Langsung}

Strategi tidak langsung atau tuturan tidak langsung adalah tuturan yang menggunakan modus kalimat yang telah mengalami peralihan fungsi konvensionalnya.

Contoh:

Sule: Oh umurnya dua, ga sawan lihat tante itu? ( menunjuk Nunung).
Pada tuturan di atas Ethes memberi tahu kepada Sule kalau umurnya saat ini dua tahun. Sule bertanya kepada Ethes. Tuturan di atas menyiratkan adanya strategi bertutur. Strategi yang digunakan adalah strategi bertutur tidak langsung dengan menggunakan kalimat tanya.

\section{Strategi Bertutur dengan Isyarat}

Strategi bertutur dengan isyarat adalah tuturan yang isinya tidak ada relevansi dengan maksud tuturan tersebut.

Contoh:

Nunung: Kayak tukang pijet tetangga saya ya Mas namanya Mbah Jambrong.

Pada tuturan di atas terdapat penggunaan strategi bertutur dengan isyarat. Tuturan Sule bermaksud untuk memberi tahu bahwa dia lupa lirik lagu yang akan dinyanyiaknnya karena lagu itu sudah lama. Sule merupakan seorang vokalis band rock dalam episode ini. Nunung menyamakan Sule dengan tukang pijet yang ada di dekat rumahnya yang bernama mbah jambrong.

Pada tuturan di atas secara literal, tuturan tersebut bermakna sindiran. Nunung mengatakan bahwa Sule mirip seperti tukang pijet di dekat rumahnya. Secara kontekstual, Nunung sebagai teman kerja Sule meminta agar Sule segera mengganti pakaiannya karena Sule dianggap tidak pantas berpenampilan seperti itu.

\section{SIMPULAN}

Berdasarkan hasil analisis data pada bab II dan III dapat ditarik suatu simpulan. Berikut adalah uraian simpulan mengenai pembahasan pada bab sebelumnya. Pada acara Ini Talk show edisi Spesial Keluarga Bapak Jokowi ditemukan lima jenis tindak ilokusi, yaitu asertif, direktif, ekspresif, komisif, dan deklaratif. Penelitian ini menemukan lima data berupa asertif, sebelas data berupa direktif, sepuluh data berupa 
ekspresif, empat data berupa komisif, tiga data berupa deklaratif.

Strategi bertutur yang ditemukan ada tiga bertutur tidak langsung, dan strategi bertutur dengan isyarat. Ada sepuluh data tuturan yang termasuk dalam strategi bertutur terdiri atas lima data berupa strategi bertutur langsung, tiga data berupa strategi bertutur tidak langsung, dan dua data berupa strategi bertutur dengan isyarat.

\section{REFERENSI}

Agustia, Fivin. 20112. Analisis Tindak Tutur dalam Kumpulan Cerpen 5Minute Barnyard Tales For Bedtime, Karya Maria Buckingham, dkk.

Ananda, Nova Avidia. 2015. Bentuk dan Fungsi Tindak Tutur Slogan Varian Iklan Pond's di Televisi Swasta. Jurnal Pendidikan Bahasa dan Sastra Indonesia. Vol: 3 No: 1.

Apriyanti, Dwi. 2015. Analisis Tindak Tutur Direktif dalam Novel Kadurakan ingKidul Dringu Karya Suparto Brata. Jurnal Humaniora. Vol 6. No 3.

Dewi. I Gusti Ayu Ratih Sintya. 2016. Jenis Bentuk dan Fungsi Tindak Tutur Meme Comic pada Facebook. Jurnal Pendidikan Bahasa dan Sastra Indonesia. Vol: 5. No: 3.

Elmita, W., Ermanto., \& Ratna, E. 2013. "Tindak Tutur Direktif Guru dalam Proses Belajar Mengajar di TK Nusa Indah Banuaran Padang". Jurnal Pendidikan Bahasa dan Sastra Indonesia. Vol. 1. No. 2.

Hidlir, Lalu Muhammad. 2013. Tindak Tutur Pengawas dalam Kegiatan Supervisi Akademik pada Guru SMA di Kabupaten Lomok Timur Tahun 2012/2013. Jurnal Pendidikan dan Pembelajaran Bahasa Indonesia. Vol 2.

Leech, Geoffrey. 1993. Prinsip-Prinsip Pragmatik. Jakarta: UI Press.

Levinson, Stephan C. 1985. Pragmatiks. Cambridge: Cambridge University Press.

Luvia, Annisa. 2016. "Tindak Tutur Ekspresif Siswa Kelas VIII SMP Negeri 27 Padang”. Jurnal Pendidikan Bahasa dan Sastra Indonesia. Vol. 2.

Moleong, Lexy J. 2000. Metodologi Penelitian Kualitatif. Bandung: PT Remaja Rosdakarya.

Muntolib. 2013. Analisis Tindak Tutur Novel Para Abdi Sami Cecaturan Karya Mas Ngabehi Wasesa Pangrarit. Jurnal Program Studi Pendidikan Bahasa dan Satra Jawa_Universitas Muhammadiyah, (02): 50-51.

Nadar, F.X. 2008. Pragmatik dan Penelitian Pragmatik. Yogyakarta: Graha Ilmu.

Ohoiwutun, Paul. 2007. Sosiolinguistik. Jakarta: Visipro.

Purnamamentari, Luh Yuli. 2017. Analisis Jenis Bentuk dan Fungsi Tindak Tutur Berita Utama pada Koran Bali Pos. Jurnal Pendidikan Bahasa dan Sastra Indonesia, Undiksha. Vol: 7 No: 2.

Putri, Meysita Nastiti. 2017. Tindak Ilokusi dan Strategi Bertutur Tokoh dalam Novel Supernova: Akar Karya Dewi Lestari. Jurnal Humanis. Vol 20. No 1.

Rahardi, Kunjana. 2005. Pragmatik: Kesantunan Imperatif Bahasa 
Imperatif Bahasa Indonesia. Jakarta: Erlangga.

Rahardi, Kunjana. 2009. Sosio Prgamatik. Jakarta: Erlangga.

Sendilatta, Ekky Cintyaresi. 2013. Analisis Tindak Tutur pada Film "Garuda di Dadaku" Karya Ifa Ifansyah. Jurnal Artikulasi. Vol. 7 No. 1.

Susseptiana, Fattrika. 2015. Analisis Tindak Tutur Direktif dalam Novel Ngulandara Karya Margana Djajaatmadja. Jurnal Humaniora. Vol 7. No 3. 